\title{
Behavioural assessment of pediatric pain
}

\author{
Ronald L Blount PhD, Kristin A Loiselle BS
}

\author{
RL Blount, KA Loiselle. Behavioural assessment of pediatric pain. \\ Pain Res Manage 2009;14(1):47-52.
}

Behavioural assessment methods have been used to signal the need for intervention and to evaluate treatment effectiveness. Direct observation and rating scales have been used to assess pain and distress associated with acute medical procedures, postoperative pain, critical care, analogue pain induction procedures and other sources. Two recent scholarly reviews of behavioural assessment methods were conducted by the Society of Pediatric Psychology Evidence-Based Assessment Task Force and the Pediatric Initiative on Methods, Measurement, and Pain Assessment in Clinical Trials, which classified various instruments as well established, approaching well established or promising. The characteristics of the eight behavioural assessment scales that were recommended by one of these task forces are further reviewed in the present paper. The results indicate that behavioural assessment scales have been used flexibly to assess pain in a wide variety of situations, across different pediatric populations and for patients of different ages. In the present review, there appears to be no basis for designating the scales as measures of distress versus pain; both emotional and sensory components of pain seem to be assessed by each of the scales. There is considerable overlap among the behavioural indicators of pain used in the different scales. Furthermore, the behavioural codes indicative of pain may occur before, during and after painful events. Recommendations for future research are provided, including using behavioural assessment to focus on children's coping and adults' behaviours, as well as pain.

Key Words: Behavioural assessment; Direct observation; Pediatric pain; Rating scale

$\mathrm{P}_{\mathrm{c}}^{\mathrm{a}}$ ain assessment can have several functions. At minimum, it can be used to indicate the need for intervention, as well as to evaluate the effectiveness of treatments designed to reduce pain. Also, pain assessment is necessary to determine the associations between levels of pain and other variables. This explicative type of research, typically conducted using correlational methods, is useful for understanding how other factors are related to pain and for constructing theoretical models of pain. Some correlated variables simply occur together with pain, while others may have a causal influence. If probable causal associations are found, results from correlation-based research could inform the design of interventions to reduce pain (1).

The two main behavioural assessment methods are direct observation and ratings by others. Using either method, assessment may be conducted live or through the use of video and audio recordings. Simple coding systems that include a limited number of code categories are more amenable to live observation, whereas more complex coding systems require some form of recording. The rate and duration of pain behaviours are more precisely measured using direct observation, while the intensity of behaviour is most easily assessed using rating scales. It is also possible to combine direct observation and rating scales, so that behaviours are coded for occurrence and also

\section{Échelles comportementales d'évaluation de la douleur pédiatrique}

Des échelles comportementales d'évaluation de la douleur ont servi d'indicateurs de la nécessité d'intervenir et d'outils de mesure de l'efficacité des traitements. L'observation directe et les échelles d'évaluation ont permis de quantifier la souffrance et la détresse associées aux interventions médicales aiguës, aux interventions chirurgicales (en période postopératoire), aux soins critiques, aux techniques d'inductions de la douleur et autres. La Society of Pediatric Psychology Evidence-Based Assessment Task Force et la Pediatric Initiative on Methods, Measurement and Pain Assessment in Clinical Trials ont récemment procédé à deux analyses scientifiques sur des méthodes d'observation du comportement et ont classé divers instruments selon qu'ils étaient bien établis, sur le point de l'être ou prometteurs. Les caractéristiques de huit échelles comportementales d'évaluation ont été utilisées avec flexibilité pour évaluer la douleur dans une vaste gamme de contextes, auprès de différentes populations de patients pédiatriques d'âges divers. Selon la présente analyse, il ne semble par y avoir lieu de distinguer les échelles selon qu'elles mesurent la détresse plutôt que la douleur; les dimensions émotionnelles et sensorielles de la douleur semblent adéquatement évaluées par les échelles. On constate un chevauchement important des indicateurs comportementaux de la douleur dans les différentes échelles. De plus, les codes comportementaux indicateurs de la douleur peuvent apparaître avant, durant et après les épisodes douloureux. Les auteurs formulent des recommandations pour la recherche future, y compris sur des évaluations des indices comportementaux qui aborderaient les mécanismes d'adaptation des enfants et les attitudes des parents, en plus de la douleur. rated for intensity. In addition, it is also possible to a priori assign intensity weightings to the code categories in the assessment instrument, as has been done with the Observation Scale of Behavioral Distress (OSBD) (2). For example, scream may be weighted higher than cry.

With behavioural assessment, determining the beginning and ending points for the observational period is necessary. This is most easily illustrated during acute painful medical procedures. Observations made during the preprocedural phase, typically starting a few minutes before needle insertion, assess anticipatory fear or anxiety. The encounter phase may include needle insertion through withdrawal. Finally, the postprocedural recovery phase may include the needle withdrawal until a few minutes have passed or until the child leaves the treatment room. These well-defined events, anchored around the injection or other painful procedures, have greatly facilitated the development of behavioural assessment methodology.

For assessing nonprocedural types of pain and distress, such as pain due to a stomach ache or sickle cell disease, some other method of determining when to observe would be needed. It is possible to use interviews to help determine whether there are temporal or other variations, such as whether pain would be more likely to occur at a given time of day, when engaging in a

Department of Psychology, University of Georgia, Athens, Georgia, USA

Correspondence: Dr Ronald L Blount, Department of Psychology, University of Georgia, Athens, Georgia 30602-3013, USA.

Telephone 706-542-1173, fax 706-542-8048, e-mail rlblount@uga.edu 
particular activity (such as getting ready for school) or when a particular person is present. To the extent that systematic variations in pain can be identified, behavioural assessment is more applicable.

Recording pain behaviours may be conducted using a continuous coding format, in which each occurrence of the behaviour is recorded. From this, rates may be determined. An interval coding system is also applicable for capturing the dimensions of rate and duration of behaviour, albeit neither is assessed perfectly. If intervals are used, it is important to keep the interval length short ( $5 \mathrm{~s}$ to $15 \mathrm{~s}$ ) to assure maximum sensitivity to variations in pain behaviour. Electronic recording and data analysis software are also available, although these can be expensive and cumbersome. For more details on behavioural assessment guidelines, refer to the publication by Bakeman and Gotmann (3).

The choice of whether to use a direct observation or rating system approach is based on a host of factors. Well-constructed direct observation systems typically provide the greatest detail, rate is a readily understood and communicated objective measure and the data can be used in a flexible manner. In contrast, rating scales have the distinct advantage of requiring less time and effort to use. For this reason, rating scales probably enjoy greater popularity in clinical settings.

\section{BEHAVIOURAL ASSESSMENT IN PEDIATRIC PAIN: TASK FORCES REVIEWS}

There have been two recent scholarly reviews in this area, the results of which will be briefly summarized below. Both groups, the Society of Pediatric Psychology Evidence-Based Assessment Task Force (SPP-EBA) on Pain Assessment (4), and the Pediatric Initiative on Methods, Measurement, and Pain Assessment in Clinical Trials (Ped-IMMPACT) (5) used the SPP-EBA's objective criteria for evidence-based assessment (6). Using the SPP-EBA criteria, assessment instruments were categorized as well established, approaching well established or promising (6). Additional criteria were used by von Baeyer and Spagrud (5). The methods used for selecting instruments to review also differed between the two groups.

The SPP-EBA used various literature search engines and reviews to compile a list of 367 measures used in eight different areas of pediatric psychology, including 25 observational measures for assessing pain in infants and children. This list was sent to the 325 subscribers on the Society's e-mail listserv with instructions to indicate the instruments that they had used; subscribers were then asked to return the document after completion. Respondents could also nominate instruments they used that were not on the list. Eighty-seven members responded. A total of six pain scales applicable for children three years of age and older received four or more endorsements, and were therefore reviewed.

The OSBD (2) and its revised version (7) received the highest number of endorsements, with 20. Additional scales included, in no particular order, the Procedural Behavior Rating Scale (PBRS) (8) and its revised version (PBRS-R) (9), the Child-Adult Medical Procedure Interaction Scale (CAMPIS) (10) and its revised version (CAMPIS-R) (11), the Procedure Behavior Checklist (PBCL) (12), the Children's Hospital of Eastern Ontario Pain Scale (CHEOPS) (13) and the COMFORT scale (14). Each scale was classified as well established, except for the PBRS, which was promising.
For the Ped-IMMPACT review, 22 scales were selected for review based on literature searches. One of the additional criteria beyond those developed by the SPP-EBA was that the scale could be used with low burden, meaning the amount of time, effort, equipment and training needed for use. The additional criteria favoured rating scales over direct observation measures. They recommended six scales for use. For procedural pain, the Face, Legs, Activity, Cry, Consolability (FLACC) scale (15) and the CHEOPS were recommended. For postoperative pain, the FLACC scale was recommended for use in the hospital and the Parents' Postoperative Pain Measure (PPPM) (16) for use at home. For pain in critical care settings, the COMFORT scale was recommended. For pain-related distress, fear and anxiety during medical procedures, the PBCL and PBRS were recommended. In this regard, von Baeyer and Spagrud (5) distinguished between the previous scales, which they considered to assess pain, and the two latter scales, which they viewed as assessing distress. We will examine the validity of this distinction later in the present article. Of the recommended scales, the PBRS was classified as promising; the PBCL and COMFORT scale were classified as approaching well established; and the CHEOPS, PPPM and FLACC scale were classified as well established. Each of the scales recommended by the two task forces will be described below, beginning with the direct observation measures and followed by the rating scales.

The PBRS (8) was developed specifically for infants and children up to 18 years of age with cancer, who were undergoing bone marrow aspirations (BMAs) or lumbar punctures (LPs). It originally contained 13 behavioural codes that were eventually reduced to 11 in the revised version - the PBRS-R (9). The behaviours assessed in the PBRS-R include cry, cling, pain verbal, flail, stall, scream, refuse position, restrain, emotional support, muscular rigidity and requests termination. Each behaviour is recorded once for occurrence during each of the four phases of a medical procedure - when the child enters the room, the prenumbing swabbing and anesthesia stick, the actual procedure until needle removal and from needle removal until the child leaves the treatment room. The PBRS has also been used to evaluate procedural pain and distress in children during treatment for burn injuries (17). One criticism of the PBRS-R is that it does not account for repeated code occurrences in the same phase, which likely decreases sensitivity of the measure to variations in pain.

Similar to the PBRS, the OSBD (2) was developed for use with children and adults two to 20 years of age requiring BMAs as part of their cancer treatment. The original OSBD included 11 operationally defined behaviours indicative of distress. The revised version (the OSBD-R) (7) contains eight of the original 11 components and demonstrates good sensitivity. The behaviours assessed in the OSBD-R include cry, scream, restraint, verbal resistance, information seeking, emotional support, verbal pain and flail. Unique to the OSBD, each behaviour is multiplied by a preassigned value based on the intensity of distress. For example, cry and information seeking are weighted at 1.5; emotional support at 2; verbal resistance and verbal pain at 2.5; and scream, restraint and flail at 4 . These distress weights reflect the average values assigned to those behaviours by medical staff who are familiar with children undergoing BMAs. Each behaviour is coded for occurrence during consecutive $15 \mathrm{~s}$ intervals during four phases of the medical procedure, yielding an average for 
each phase. The phases include the waiting period before starting the procedure, the preparation period (including positioning the child and antiseptic washing), the actual procedure beginning with the first needle stick until final needle withdrawal, and the time immediately following the procedure. The total score from each phase is averaged, and then added to yield an overall distress score. Since its development, the OSBD has been extended to evaluate behavioural responses to burn dressing changes (18) and various painful medical procedures (implanted port access, venipuncture, intramuscular injection and subcutaneous injection) in children with illnesses such as cancer, sickle cell disease and idiopathic thrombocytopenia (19).

The PBCL (12), initially developed for children six to 18 years of age, uses eight behaviours to evaluate medical procedurerelated pain and anxiety. In subsequent research, the PBCL has been used with children as young as three years of age. The behaviours assessed in the PBCL include muscle tension, screaming, crying, restraint used, pain verbalized, anxiety verbalized, verbal stalling and physical resistance. Behaviours are scored based on occurrence ( 1 if present and 0 if absent, for a possible total score ranging from 0 to 8 per phase) and intensity (scale of 1 to 5 , where 1 indicates 'very mild' and 5 indicates 'extremely intense', for a possible total score ranging from 0 to 40 per phase) during three phases of the procedure. The three phases include when the child enters the treatment room until aspiration site cleansing, from needle insertion to removal and from needle removal to the child's exit from the treatment room. The PBCL score is derived from the three occurrence subscores and the three intensity subscores. This scale has been used to assess children undergoing BMAs $(12,20)$, LPs $(21,22)$ and venipuncture (23).

The CAMPIS (10) and the CAMPIS-R (11) were developed to evaluate behavioural distress in children associated with medical procedures, specifically BMAs and LPs. The CAMPIS child codes were developed for children two to 13 years of age, while the adult codes may be used with adults present with children as young as six months of age. In addition to child pain and distress, the CAMPIS also considers child coping, other child behaviours, and the behaviour of parents and staff during medical procedures. The CAMPIS includes 35 coding categories allocated into six areas in the CAMPIS-R. In addition to being used to code child distress (crying, screaming, verbal resistance, request emotional support, verbal fear, verbal pain, verbal emotion and information seeking), the CAMPIS can be used to code child coping (making coping statement, nonprocedure-related talk by the child, audible deep breathing and humour by the child), child neutral (child informs about status, request relief from nonprocedural discomfort, assertive procedural verbalization and child's general condition-related talk) and the adult behaviours of adult coping promoting, adult distress promoting and adult neutral behaviours. Each variable is assessed continuously or using a $5 \mathrm{~s}$ interval coding system during three phases, yielding high sensitivity: up to 3 min before the procedure, during the procedure and up to $2 \mathrm{~min}$ following the procedure. The CAMPIS has been applied to procedures including BMAs and LPs $(10,24)$, immunizations (25-29), painful physical therapy sessions (30), voiding cystourethrogram procedures (31) and analogue pain tasks (32).

The CHEOPS (13) was developed for use in the postoperative setting for children one to 12 years of age, but has been applied to other acute pain situations, such as immunizations $(33,34)$, venipuncture $(35,36)$, fracture reduction (37) and laceration repair (38). The CHEOPS assesses six behaviours that include cry, facial, child verbal, torso, touch and legs. Each behaviour is coded on a scale of 0 to 3 based on intensity. Since its development, the CHEOPS has been used as an outcome measure in studies evaluating newborns and adolescents up to 17 years of age.

The FLACC scale was initially developed for use in postoperative pain in children four to 18 years of age (15). It includes an assessment of face, legs, activity, cry and consolability as indicators of pain. Each of these five operationally defined categories is given a score from 0 to 2 , yielding a total possible range of 0 to 10 . The FLACC scale has been used with a variety of populations and ages including children in the neonatal intensive care unit (39), preverbal children (40) and children with cognitive impairment (41), as well as with pediatric postoperative pain (42).

The COMFORT scale (14), a measure of behavioural and physiological domains, was developed for use in the intensive care environment to signal the need for sedation to relieve distress, and is applicable for the assessment of children from birth to 18 years of age. The COMFORT scale assesses eight domains thought to be indicative of pain and distress including alertness, calmness/agitation, respiratory response, physical movement, mean arterial blood pressure, heart rate, muscle tone and facial tension. Each dimension is scored between 1 and 5 , and the scores are added to yield a measure of sedation. There are two main subscales - behavioural distress and physiological distress. The COMFORT scale has also been used to assess postoperative pain (43).

The PPPM (16) is a unique measure that allows parents to rate postoperative pain cues of children seven to 12 years of age at home. Parents are asked to assess 15 items that include whine or complain more than usual, cry more easily than usual, play less than usual, not do the things s/he normally does, act more worried than usual, act more quiet than usual, have less energy than usual, refuse to eat, eat less than usual, hold the sore part of his/her body, try not to bump the sore part, groan or moan more than usual, look more flushed than usual, want to be close to parent more and takes medication when normally refuses. Each domain is scored as 0 (no) or 1 (yes). Parents complete the measure following several hours of observation at designated time periods for two days following surgery. The PPPM has been extended beyond the postsurgical setting and used in assessing pediatric chronic pain $(44,45)$. The PPPM is also of value when assessing pain and distress in nonverbal populations (46).

\section{SUMMARY AND IMPRESSIONS ON BEHAVIOURAL ASSESSMENT OF PAIN AND BEHAVIOURAL DISTRESS}

Following a review of these measures, conclusions can be made about the pain behaviours that are assessed, the degree of flexibility with which the scales are used, and the phases or intervals of observation. As shown in Table 1, cry was included in seven of the eight pain scales, and scream and pain verbal were included in six. The behaviours of verbal resistance and physical restraint were included in five scales, and muscular rigidity was included in four. The codes of fear/anxiety, information seeking, facial expression/tension and flail were 
TABLE 1

Pain behaviours used in direct observation measures

\begin{tabular}{|c|c|c|c|c|c|c|c|c|}
\hline Behavioural code & PBRS-R & OSBD-R & PBCL & CAMPIS-R & CHEOPS & FLACC scale & COMFORT scale & PPPM \\
\hline Cry & घ & - & घ & घ & घ & घ & & घ \\
\hline Scream & - & - & - & - & Cry: Scream & Screams/sobs & & \\
\hline Pain verbal & - & - & ! & - & Child verbal: Pain complaint & & $\begin{array}{l}\text { Whine, } \\
\text { complain }\end{array}$ & \\
\hline Physical restraint & - & - & - & $\begin{array}{l}\text { Also } \\
\text { used }\end{array}$ & Touch and legs: Restrain & & & \\
\hline $\begin{array}{l}\text { Verbal resistance/requests } \\
\text { termination }\end{array}$ & - & - & - & - & Child verbal: Other complaints & & & \\
\hline Flail & - & घ & & & & Legs: Kicking & & \\
\hline Muscular rigidity & - & & Muscle tension & & Torso: Tense & & Muscle tone & \\
\hline Seeks emotional support & - & - & & - & & & & $\begin{array}{l}\text { Be close to } \\
\text { parent }\end{array}$ \\
\hline Fear/anxiety verbal & & & घ & घ & Other verbal: Other complaint & & & \\
\hline Information seeking & - & - & & - & & & & \\
\hline Stall/refuse position & - & & - & & & & & \\
\hline Verbal emotion & & & & - & & & & \\
\hline Facial expression/tension & & & & & Smile, grimace, composed & $\begin{array}{l}\text { Grimace, quiver, } \\
\text { clenched jaw }\end{array}$ & Facial tension & \\
\hline Legs & & & & & $\begin{array}{l}\text { Neutral, squirming, drawn up, } \\
\text { standing, restrained }\end{array}$ & $\begin{array}{l}\text { Relaxed, restless, } \\
\text { kicking, drawn up }\end{array}$ & & \\
\hline Consolability & & & & & & घ & & \\
\hline
\end{tabular}

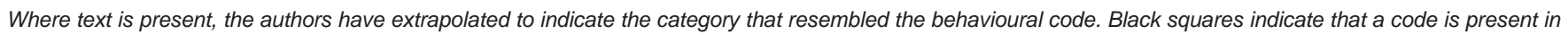

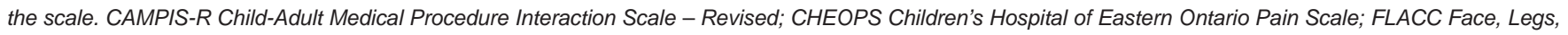

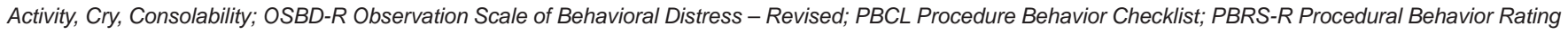
Scale - Revised; PPPM Parents' Postoperative Pain Measure

included in three of the eight scales. Finally, items that were included in only one or two of the eight scales included legs, verbal emotion, consolability, and many of the unique codes of the COMFORT scale and the PPPM.

The behaviours included in the various scales essentially describe pain researchers' consensus as to what pediatric pain looks like to an observer, or at least how it should be monitored using behavioural assessment scales. Assuming the child is verbal and conscious, there is a high degree of consensus that the behaviours of cry, scream and pain verbal are indicative of pain and should be included in observational measures of pain. There is also a strong agreement that verbal resistance, physical resistance and muscular rigidity are important behaviours to observe during the assessment of pain, assuming that the child is conscious, verbal, and able to guard or resist. Although items such as fear/anxiety, information seeking, facial expression/tension and flail were endorsed less frequently, they are still valuable behaviours to assess, depending on the type of research being conducted. Finally, it is important to note that the behaviours present in only one or two of the eight scales offered unique contributions to those inventories. A lack of consensus does not necessarily mean a lack of validity for those codes.

There is great flexibility in the settings, illness populations and types of pain with which behavioural assessment measures of pain have been used, regardless of the particular purpose for which they were developed. The direct observation scales designed primarily for assessing pain during BMAs have been used with a wide range of acute painful procedures, as well as for analogue pain assessment. Also, measures intended for use in the postoperative setting, particularly the CHEOPS, have been adapted for use in procedural pain situations. There is also good evidence supporting the validity of the behavioural assessment scales across a wide age range, from early childhood through late adolescence. Some of the scales have also been used for assessment in nonverbal populations, particularly children who are on mechanical ventilation or in the pediatric intensive care unit. In short, the evidence is encouraging regarding the feasibility of adapting existing scales for use in new situations beyond those in which they have currently been employed, including chronic pain. As long as scientific issues are adequately considered, this flexibility in usage should be viewed as a strength of the behavioural assessment scales.

Finally, the intervals within which behaviours are assessed vary according to the particular pain situation. Shorter time intervals have been indicated for acute pain assessment, such as procedural pain, while longer intervals are typically associated with postoperative and critical care settings. Scales that are generally used in the acute procedural pain setting, including the PBCL, PBRS-R, OSBD-R and the CAMPIS-R, assess behaviour during phases that occur 2 min to 3 min before the needle stick, during the needle stick and several minutes following needle removal. The OSBD/OSBD-R and CAMPIS/CAMPIS-R assess behaviours at multiple intervals within those phases, and thus have greater sensitivity than the PBRS, which assesses behaviour only once per phase. The PBCL compensates for once per interval assessment by also including a 0 to 5 intensity rating for each behavioural code, thus providing a greater range of scores and greater sensitivity. Postoperative and critical care assessment scales (ie, CHEOPS, FLACC scale, COMFORT scale and PPPM) generally use a longer assessment interval following the painful event. Postoperative and critical care pain are not anchored by impending, occurring or immediately ended medical events, but rather result from procedures that occurred hours ago. Without a peak of pain during an acute procedure, longer 
periods of observation are needed. However, the CHEOPS has also been applied to acute pain assessment and used in $5 \mathrm{~s}$ intervals. Overall, there is considerable flexibility in the phases and time intervals of observation.

There is an important conceptual issue in the field of behavioural assessment of pediatric pain as to whether some scales primarily measure pain and others primarily measure behavioural distress, or whether pain and behavioural distress should be separated. At this point, based on the behaviours that have been used in the instruments reviewed, there appears to be no basis for calling one scale a measure of pain rather than distress, or vice versa. There is considerable overlap among the behavioural indicators of pain used in the different scales. Many of these behaviours do not appear to have specificity as an indicator of pain or distress. For example, cry and scream - two of the most used codes in the behavioural assessment of pain - can occur before, during or after an injection, and can be driven primarily by fear, distress or pain. Likewise, information seeking can occur before or during injections ('What are you going to do?' versus 'What are you doing?') and can be in response to fear or pain. Finally, observable physiological indicators, such as a grimace or clenched jaw, tense or moving legs or torso, or needing restraint, can be indicative of fear or pain, and can occur in the anticipatory or encounter phase of a medical procedure. Our recommendation is that each of the scales should be viewed as a measure of pain and distress, regardless of the title of the scale. Clinicians and researchers should be especially aware of this point and not be misled by the names of scales or how they have traditionally been considered. We do not consider this stance to be problematic, given the International Association for the Study of Pain (IASP) definition of pain as including both sensory and emotional (distress) components: "Pain is an unpleasant sensory and emotional experience associated with actual or potential tissue damage, or described in terms of such" (47).

The IASP's definition of pain also refers to actual or potential tissue damage, which seems to indicate a current and a future dimension, respectively. However, an argument can be made that pre-encounter behavioural distress should be viewed as fear and anxiety more than pain, which would occur during the encounter phase. Several factors reduce the strength of that assertion. First, anticipatory phase distress has been found to have a positive correlation of 0.86 with distress during later painful BMAs (11). This suggests that distress could be viewed as a chain of behaviours rather than as a different type of behaviour. Second, although the proportion of anticipatory distress (information seeking, emotional support and verbal fear) was higher in the anticipatory phase and demonstrative distress (cry, scream, verbal resistance, verbal pain and verbal emotion) was higher during the BMA, both types of distress occurred during the preprocedural and encounter phases. Furthermore, it is possible that these differing proportions of the types of distress may represent different intensities of distress rather than categorically different dimensions. Finally, anticipatory distress may be thought of as classically conditioned distress, with anticipatory distress being a conditioned response to cues in the pre-encounter medical environment. In this regard, it is important to remember that a conditioned response is a close approximation of the original unconditioned response - the pain of the procedure. If the medical procedure is painful, then preprocedural anticipatory distress also represents pain. This is analogous to Pavlov's dog, who salivated to meat powder and also salivated to the conditioned stimulus - the bell. Pain, like salivation, occurs from both conditioned and unconditioned stimuli.

Future research in this area should continue to expand the horizons in which behavioural observation is used to assess pain. Cross-cultural research poses a host of interesting questions about behavioural displays of pain. Thus far, much of the research in this area has been done in developed countries, many of which have a strong influence from European culture. Are there unique behavioural displays of pain in cultures that are considerably different from those in which behavioural assessment has most often been used thus far? Conversely, are behavioural indicators of pain more universal in their nature, at least given normal life events and the absence of severe stressors such as war, neglect or abuse?

We noted at the beginning of the present article that pain assessment may serve several purposes. It appears that research in this area has fulfilled some of those functions more effectively than others. Behavioural assessment has effectively been used to indicate the need for intervention and evaluate the effectiveness of interventions to reduce pain. In terms of the development of conceptual or theoretical models of pain, more work needs to be done. A final function of behavioural assessment is to inform the design of treatment programs to reduce pain. Because most assessment instruments focus exclusively on the dependent variable of pain, they are not capable of informing the design of treatment interventions without additional measures being used. We recommend that the behavioural assessment of pain be combined with the behavioural assessment of child and adult behaviours that seem to function as coping and coping promoting behaviours, respectively. There are also adult behaviours that enhance distress, and these too may be worthy targets of assessment. Adult behaviours are potent predictors of children's pain reactions (48). This process of incorporating child coping and adult behaviours with behaviours indicative of pediatric pain, as related to the development of the CAMPIS has been described elsewhere (1). Similar approaches have been used in the development of the perioperative version of the CAMPIS (49). We also provide general guidelines regarding focusing on coping in the discussion section of the recent SPPEBA report on evidence-based assessment of coping and stress (50). There are other potentially heuristic guides for facilitating research in this area $(51,52)$. The addition of a focus on children's coping and adults' behaviours would provide an expanded role for behavioural assessment in the study of pediatric pain.

\section{REFERENCES}

1. Blount RL, Bunke VL, Zaff JF. Bridging the gap between explicative and treatment research: A model and practical implications. J Clin Psych Med Set 2000;7:79-90.

2. Jay SM, Ozolins M, Elliot C, Caldwell S. Assessment of children's distress during painful medical procedures. Health Psychol 1983;2:133-47.

3. Bakeman R, Gottman J. Observing Interaction: An Introduction to Sequential Analysis, 2nd edn. New York: Cambridge University Press, 1997.

4. Cohen LL, Lemanek K, Blount RL, et al. Evidence-based assessment of pediatric pain. J Pediatr Psychol 2008;33:939-55.

5. von Baeyer CL, Spagrud LJ. Systematic review of observational (behavioral) measures of pain for children and adolescents aged 3 to 18 years. Pain 2007;127:140-50.

6. Cohen LL, La Greca AM, Blount RL, Kazak AE, Holmbeck GN, Lemanek KL. Introduction: Evidence-based 
assessment in pediatric psychology. J Pediatr Psychol 2008;33:911-5.

7. Elliot CH, Jay SM, Woody P. An observational scale for measuring children's distress during medical procedures. J Pediatr Psychol 1987;12:543-51.

8. Katz ER, Kellerman J, Siegel SE. Behavioral distress in children with cancer undergoing medical procedures: Developmental considerations. J Consult Clin Psychol 1980;48:356-65.

9. Katz ER, Kellerman J, Ellenberg L. Hypnosis in the reduction of acute pain and distress in children with cancer. J Pediatr Psychol 1987;12:379-94.

10. Blount RL, Corbin SM, Sturges JW, Wolfe VV, Prater JM, James LD. The relationship between adults' behavior and child coping and distress during BMA/LP procedures: A sequential analysis. Behav Ther 1989;20:585-601.

11. Blount RL, Sturges JW, Powers SW. Analysis of child and adult behavioral variations by phase of medical procedure. Behav Ther $1990 ; 21: 33-48$

12. LeBaron S, Zeltzer L. Assessment of acute pain and anxiety in children and adolescents by self-reports, observer reports, and a behavior checklist. J Consult Clin Psychol 1984;52:729-38.

13. McGrath PJ, Johnson G, Goodman JT, Dunn J, Chapman J. CHEOPS: A behavioral scale for rating postoperative pain in children. In: Fields HL, Dubner R, Cervero F, eds. Advances in Pain Research and Therapy. New York: Raven Press, 1985:395-402.

14. Ambuel B, Hamlett KW, Marx CM, Blumer JL. Assessing distress in pediatric intensive care environments: The COMFORT scale. J Pediatr Psychol 1992;17:95-109.

15. Merkel SI, Voepel-Lewis T, Shayevitz JR, Malviya S. The FLACC: A behavioral scale for scoring postoperative pain in young children. Pediatr Nurs 1997;23:293-7.

16. Chambers CT, Reid GJ, McGrath PJ, Finley GA. Development and preliminary validation of a postoperative pain measure for parents. Pain 1996;68:307-13.

17. Elliott $\mathrm{CH}$, Olson RA. The management of children's distress in response to painful medical treatment for burn injuries. Behav Res Ther 1983;21:675-83.

18. Foertsch CE, O'Hara MW, Stoddard FJ, Kealey GP. Treatment resistant pain and distress during pediatric burn-dressing changes. J Burn Care Rehabil 1998;19:219-24.

19. Tucker CL, Slifer KJ, Dahlquist LM. Reliability and validity of the Brief Behavioral Distress Scale: A measure of children's distress during invasive medical procedures. J Pediatr Psychol 2001;26:513-23.

20. Pfefferbaum F, Adams J, Aceves J. The influence of culture on pain in Anglo and Hispanic children with cancer. J Am Acad Child Adolesc Psychiatry 1990;29:642-7.

21. Chen E, Craske MG, Katz ER, Schwartz E, Zeltzer LK. Pain-sensitive temperament: Does it predict procedural distress and response to psychological treatment among children with cancer? J Pediatr Psychol 2000;25:269-78.

22. Liossi C, Hatira P. Clinical hypnosis in the alleviation of procedurerelated pain in pediatric oncology patients. Int J Clin Exp Hypn 2003;51:4-28.

23. Schiff WB, Holtz KD, Peterson N, Rakusan T. Effect of an intervention to reduce procedural pain and distress for children with HIV infection. J Pediatr Psychol 2001;26:417-27.

24. Dahlquist LM, Power TG, Carlson L. Physician and adult behavior during invasive pediatric cancer procedures: Relationship to child behavioral distress. J Pediatr Psychol 1995;20:477-90.

25. Blount RL, Bachanas, PJ, Powers SW, et al. Training children to cope and parents to coach them during routine immunizations: Effects on child, parent and staff behaviors. Behav Ther 1992;23:689-705.

26. Blount RL, Cohen LL, Frank NC, et al. The Child-Adult Medical Procedure Interaction Scale-Revised: An assessment of validity. J Pediatr Psychol 1997;22:73-88.

27. Cohen LL, Blount RL, Panopoulos G. Nurse coaching and cartoon distraction: An effective and practical intervention to reduce child, parent, and nurse distress during immunizations. J Pediatr Psychol 1997;22:355-70.

28. Cohen LL, Blount RL, Cohen RJ, Schaen ER, Zaff JF. A comparative study of distraction versus topical anesthesia for pediatric pain management during immunizations. Health Psychol 1999;18:591-8.

29. Sweet SD, McGrath PJ. Relative importance of mothers' versus medical staffs' behavior in the prediction of infant immunization pain behavior. J Pediatr Psychol 1998;23:249-56.
30. Miller AC, Johanna-Murphy M, Zhelezniak V. Impact of therapistchild dyad on children's pain and coping during medical procedures. Dev Med Child Neurol 2001;43:118-23.

31. Zelikovsky N, Rodrigue JR, Gidyzc CA, Davis MA. Cognitive behavioral and behavioral interventions to help children cope during voiding cystourethrogram. J Pediatr Psychol 2000;25:535-43.

32. Chambers CT, Craig KD, Bennett SM. The impact of maternal behavior on children's pain experience: An experimental analysis. J Pediatr Psychol 2002;27:293-301.

33. Cassidy KL, Reid, GJ, McGrath PJ, et al. Watch needle, watch TV: Audiovisual distraction in preschool immunization. Pain Med 2002;3:108-18.

34. Cassidy KL, Reid GJ, McGrath PJ, Smith DJ, Brown TL, Finley GA. A randomized double-blind, placebo-controlled trial of the EMLA patch for the reduction of pain associated with intramuscular injections in four to six-year-old children. Acta Paediatr 2001;90:1329-36.

35. Galinkin JL, Rose JB, Harris K, Watcha MF. Lidocaine iontophoresis versus eutectic mixture of local anesthetics (EMLA) for IV placement in children. Anesth Analg 2002;94:1484-8.

36. Van-Cleve L, Jonson L, Pothier P. Pain responses of hospitalized infants and children to venipuncture and intravenous cannulation. J Pediatr Nurs 1996;11:161-7.

37. McCarty EC, Mencio GA, Walker LA, Green NE. Ketamine sedation for the reduction of children's fractures in the emergency department. J Bone Joint Surg Am 2000;82:912-8.

38. Klein EJ, Diekema DS, Paris CA, Quan L, Cohen M, Seidel KD. A randomized, clinical trial of oral midazolam plus placebo versus oral midazolam plus oral transmucosal fentanyl for sedation during laceration repair. Pediatrics 2002;109:894-7.

39. Ahn Y, Jun Y. Measurement of pain-like response to various NICU stimulants for high-risk infants. Early Hum Dev 2007;83:255-62.

40. Manworren RC, Hynan LS. Clinical validation of FLACC: Preverbal patient pain scale. Pediatr Nurs 2003;29:140-6.

41. Voepel-Lewis T, Malviya S, Tait AR. Validity of parent ratings as proxy measures of pain in children with cognitive impairment. Pain Manag Nurs 2005;6:168-74.

42. Willis MHW, Merkel SI, Voepel-Lewis T, Malviya S. FLACC behavioral pain assessment scale: A comparison with a child's self-report. Pediatr Nurs 2003;29:195-8.

43. van Dijk M, de Boer J, Koot H, Tibboel D, Passchier J, Duivenvoorden $\mathrm{H}$. The reliability and validity of the COMFORT scale as a postoperative pain instrument in 0 to 3 -year-old infants. Pain 2000;84:367-77.

44. Hunfeld JA, van der Wouden JC, den Deuwaarder ES, van Suijlekom-Smit LW, Hazebroek-Kampschreur AA. Measuring chronic pain in children, an exploration. Percept Mot Skills 1997;84:1176-8.

45. Perquin CW, Hunfeld JA, Hazebroek-Kampschreur AA, et al. Insights in the use of health care services in chronic benign pain in childhood and adolescence. Pain 2001;94:205-13.

46. Breau LM, McGrath PJ, Camfield C, Rosmus C, Finley GA. Preliminary validation of an observational pain checklist for persons with cognitive impairments and inability to communicate verbally. Dev Med Child Neurol 2000;42:609-16.

47. International Association for the Study of Pain Subcommittee on Taxonomy. Pain terms: A list with definitions and notes on usage. Pain 1979;6:249-52.

48. Frank NC, Blount RL, Smith A, Manimala MR, Martin JK. Parent and staff behavior, previous child medical experience, and maternal anxiety as they relate to child distress and coping. J Pediatr Psychol 1995;20:277-89.

49. Caldwell-Andrews AA, Blount RL, Mayes LC, Kain ZN. Behavioral interactions in the perioperative environment: A new conceptual framework and the development of the Perioperative Child-Adult Medical Procedure Interaction Scale. Anesthesiology 2005;103:1130-5.

50. Blount RL, Simons LE, Devine KA, et al. Evidence-based assessment of coping and stress in pediatric psychology. J Pediatr Psychol 2008;33:1021-45.

51. Breau LM. A bio-ecological approach to pediatric pain assessment. J Pain Manage 2009. (In press)

51. Franck LS, Greenberg CS, Stevens B. Pain assessment in infants and children. Pediatr Clin North Am 2000;47:487-512. 


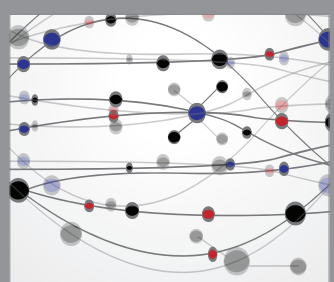

The Scientific World Journal
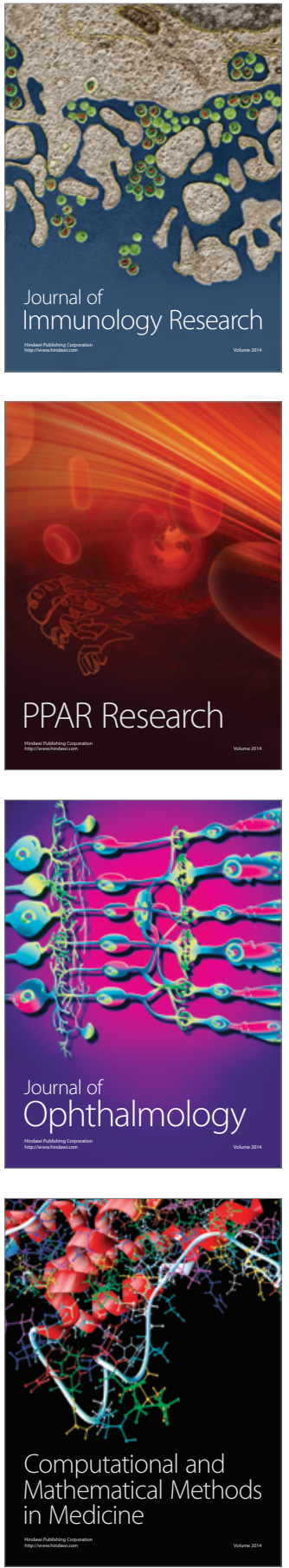

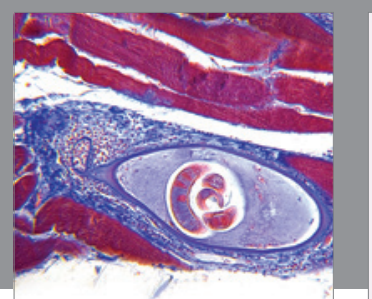

Gastroenterology Research and Practice

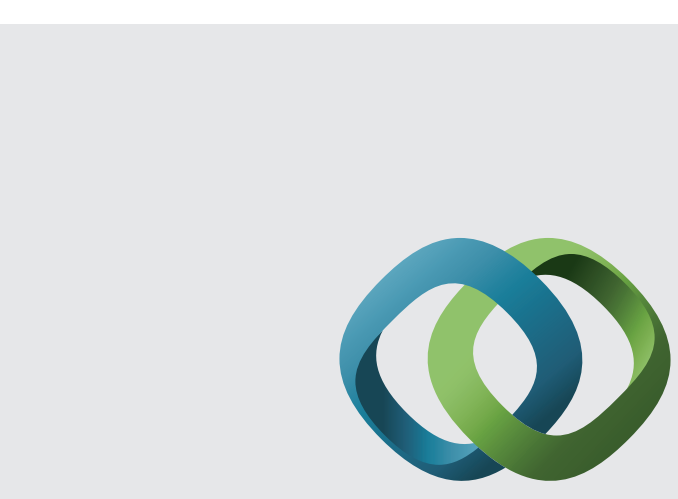

\section{Hindawi}

Submit your manuscripts at

http://www.hindawi.com
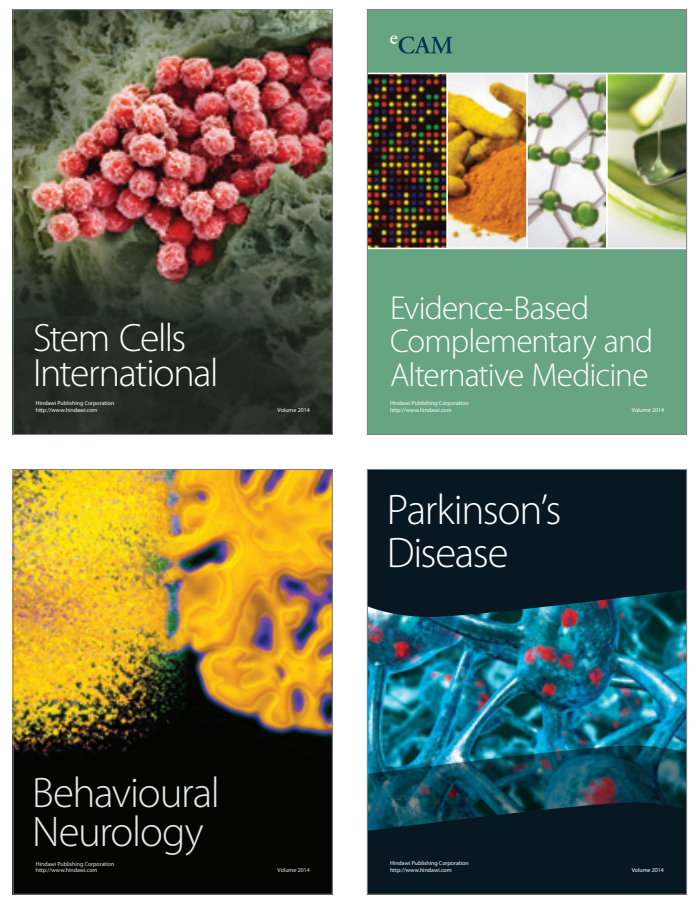
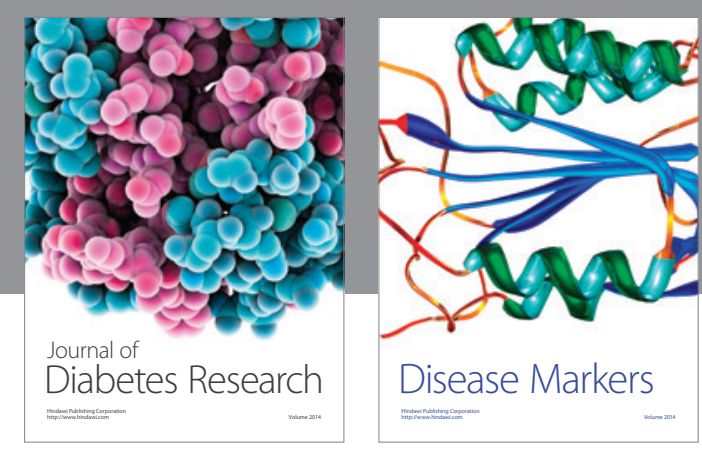

Disease Markers
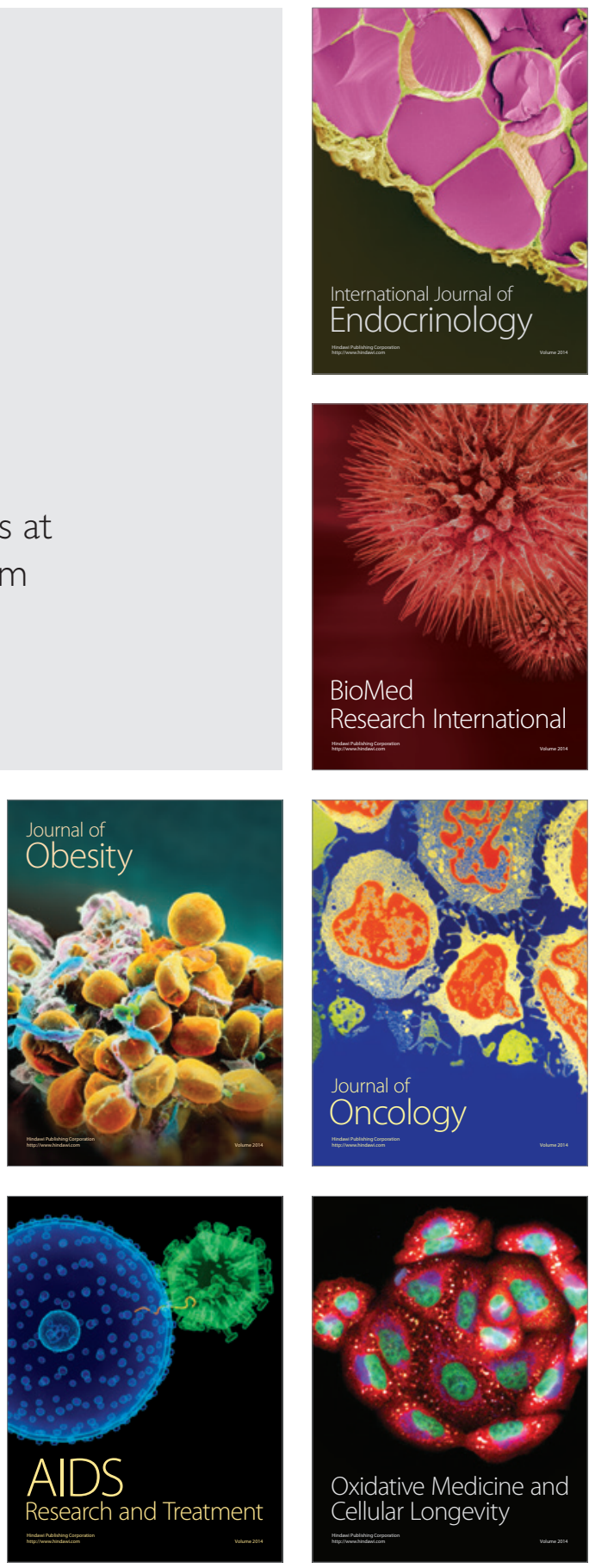